\title{
Efeito do ácido peracético sobre a adesão microbiana e as propriedades de tubos endotraqueais
}

\author{
Effect of peracetic acid on microbial adhesion and on properties of \\ endotracheal tubes
}

\author{
Ana Paula Poletto* \\ Júlia Hoss* \\ Siméri Isabel Wermuth* \\ Fernando Freitas Portella* \\ Rodrigo Alex Arthur ${ }^{* * *}$ \\ Deise Ponzoni**** \\ Susana Maria Werner Samuel ${ }^{* * * * *}$ \\ Edela Puricelli*****+
}

\section{Resumo}

Objetivo: avaliar a influência do número de imersões em ácido peracético na colonização bacteriana, na composição química, na rugosidade e na capacidade de recuperação após a deformação de tubos endotraqueais. Materiais e método: quatro tubos foram submetidos a sucessivas imersões em ácido peracético, constituindo quatro grupos: um controle (esterilizado pelo fabricante) e outros submetidos a uma, duas ou três imersões, de forma a simular o reprocessamento dos tubos. Os ensaios realizados foram: espectroscopia de infravermelho, rugosidade superficial, deformação da luz do tubo após compressão e colonização por Staphylococcus aureus. Resultados: o número de imersões (reprocessamento) não influenciou a colonização dos tubos por Staphylococcus aureus $(p=0,235)$, nem a composição química, nem a rugosidade $(p=0,621)$. Além disso, não houve diferença na capacidade do tubo em recuperar-se após deformação $(p=0,633)$. Conclusão: o reprocessamento por até três vezes não traz prejuízo às propriedades do material e não aumenta a colonização bacteriana na superfície dos tubos.

Palavras-chave: Ácido peracético. Desinfecção. Pneumonia associada à ventilação mecânica. Respiração artificial.

\section{Introdução}

Tubos endotraqueais são amplamente utilizados em anestesias e equipamentos de ventilação mecânica no âmbito hospitalar. Sabe-se que pacientes intubados por longos períodos têm aumentado o risco de desenvolver pneumonia nosocomial ${ }^{1}$, prolongando em mais de cinco dias o tempo de hospitalização ${ }^{2}$. A pneumonia nosocomial representa uma das causas mais prevalentes de morte em decorrência de infecções hospitalares ${ }^{3}$. Quando a condição respiratória do paciente está deteriorada, a intubação pode levar o paciente a um risco de aspiração de patógenos até o trato respiratório inferior, levando ao desenvolvimento de pneumonia associada à ventilação mecânica (PAVM), que ocorre devido à aspiração de secreções da orofaringe, do condensado formado no circuito do respirador ou do conteúdo gástrico colonizado por bactérias patogênicas ${ }^{4}$. Nesse sentido, o tubo endotraqueal por si só proporciona uma superfície passível de colonização bacteriana e formação de biofilme, de onde, posteriormente, microrganismos podem ser broncoaspirados ${ }^{2}$. Após 72 horas de intubação, já são encontradas cepas de Staphylococcus aureus nos tubos endotraqueais e na boca

Acadêmicas de Odontologia. Programa de Educação Tutorial, Faculdade de Odontologia, Universidade Federal do Rio Grande do Sul, Porto Alegre, RS, Brasil. Doutor em Odontologia. Universidade Aberta do SUS, Universidade Federal de Ciências da Saúde de Porto Alegre, Porto Alegre, RS, Brasil.

Doutor em Odontologia. Laboratório de Bioquímica e Microbiologia, Faculdade de Odontologia, Universidade Federal do Rio Grande do Sul, Porto Alegre, RS, Brasil.

*** Doutora em Odontologia. Unidade de Cirurgia e Traumatologia Bucomaxilofacial do Hospital de Clínicas de Porto Alegre, Porto Alegre, RS, Brasil. Departamento de Cirurgia e Ortopedia, Faculdade de Odontologia, Universidade Federal do Rio Grande do Sul, Porto Alegre, RS, Brasil.

Doutora em Materiais Dentários. Programa de Educação Tutorial, Faculdade de Odontologia, Universidade Federal do Rio Grande do Sul, Porto Alegre, RS, Brasil. Laboratório de Materiais Dentários, Faculdade de Odontologia, Universidade Federal do Rio Grande do Sul, Porto Alegre, RS, Brasil.

****** Doutora. Unidade de Cirurgia e Traumatologia Buco-maxilo-facial do Hospital de Clínicas de Porto Alegre, Porto Alegre, RS, Brasil. Instituto Puricelli \& Associados, Porto Alegre, RS, Brasil. 
do paciente intubado, sendo esses microrganismos associados à PAVM ${ }^{5}$.

Os tubos para ventilação endotraqueal são classificados como itens semicríticos ${ }^{6}$ e destinados ao uso único. Todavia, é de conhecimento a sua reutilização como forma de redução dos custos de cuidados em saúde ${ }^{7,8}$. De acordo com a Food and Drug Administration (FDA), para a reutilização desses aparatos, é necessária uma desinfecção de alto nível, podendo essa ser realizada em autoclave ou com soluções desinfetantes ${ }^{9}$.

$\mathrm{O}$ ácido peracético tem sido usado na esterilização automatizada de artigos médicos e cirúrgicos, com as vantagens de não ser inativado na presença de matéria orgânica, não deixar resíduos nos materiais e não produzir subprodutos nocivos ${ }^{10,11}$. O ácido peracético parece ser uma opção na área de biossegurança, especialmente em relação a materiais termossensíveis, e apresenta comprovada capacidade desinfetante e eficácia contra vírus, bactérias e esporos ${ }^{11}$. Contudo, ainda não se sabe o efeito de repetidas imersões em ácido peracético na integridade física e química dos tubos de policloreto de vinila (PVC) utilizados para intubação endotraqueal.

Considerando o exposto, o objetivo deste estudo foi avaliar a influência do número de imersões em ácido peracético na colonização bacteriana, na composição química, na rugosidade e na capacidade de recuperação após a deformação de tubos endotraqueais.

\section{Materiais e método}

O projeto foi aprovado pela Comissão Científica do Grupo de Pesquisa e Pós-Graduação do Hospital de Clínicas de Porto Alegre (Projeto no 130292) e pelo Comitê de Ética em Pesquisa - Plataforma Brasil (CCAE no 27036314.7.0000.5327). Trata-se de um estudo experimental laboratorial in vitro realizado com tubos endotraqueais fornecidos pelo Hospital de Clínicas de Porto Alegre (HCPA). O processamento dos tubos foi realizado na Central de Esterilização do HCPA e os ensaios laboratoriais no Laboratório de Materiais Dentários e no Laboratório de Bioquímica e Microbiologia Bucal, ambos localizados na Faculdade de Odontologia da Universidade Federal do Rio Grande do Sul. Foram utilizados quatro tubos endotraqueais não aramados, de calibre 6,5 mm, constituídos de PVC (Rüsch ${ }^{\circledR}$, Teleflex Medical Company).

\section{Processamento com ácido peracético dos tubos e obtenção das amostras}

Os tubos foram submetidos a sucessivas imersões em ácido peracético, constituindo quatro grupos: um grupo controle (tubo novo, esterilizado pelo fabricante) e outros submetidos a um, dois ou três ciclos de imersão. O processamento dos tubos foi realizado na Central de Esterilização do HCPA pela enfermeira responsável, utilizando o mesmo protocolo adotado rotineiramente. $\mathrm{O}$ protocolo consiste em imergir completamente o tubo em ácido peracético $0,15 \%$ por 20 minutos, enxaguar e secar com compressas e ar comprimido.

Após o processo de imersão, os tubos foram seccionados transversalmente de forma que se obtivessem quarenta corpos de prova cilíndricos com $10 \mathrm{~mm}$ de altura. Posteriormente, vinte cilindros foram seccionados no longo eixo do tubo, de forma a se obter quarenta semicilindros planificados em uma área de $100 \mathrm{~mm}^{2}$. A manipulação dos tubos para o preparo dos corpos de prova foi feita sob condições estéreis em capela de fluxo laminar. Obteve-se, para cada grupo experimental, dez semicilindros (cinco destinados ao ensaio de contaminação da superfície com Staphylococcus aureus e cinco para os ensaios de infravermelho e rugosidade). Os cinco cilindros restantes de cada grupo experimental foram utilizados no ensaio de recuperação após deformação.

\section{Contaminação dos tubos com Staphylococcus aureus}

Staphylococcus aureus (ATCC 29213) foram reativados a partir de estoques congelados em Brain Hearth Infusion (BHI) e 10\% de glicerol. Alíquotas de $100 \mu \mathrm{L}$ dos estoques foram inoculadas em placas de Agar Sangue (AS), suplementada com 5\% de sangue de carneiro desfibrilado e incubadas a $37^{\circ} \mathrm{C}$, por 24 horas. Em seguida, colônias bacterianas foram coletadas e transferidas para um tubo contendo meio BHI suplementado com $0,5 \%$ de glicose e incubado a $37^{\circ} \mathrm{C}$, por 24 horas. Os corpos de prova para os quatro grupos experimentais foram assepticamente transferidos para uma placa de 24 poços e cobertos por $2,0 \mathrm{~mL}$ de meio BHI $+0,5 \%$ glicose. Cerca de $500 \mu \mathrm{L}$ da suspensão bacteriana foram adicionados a cada poço ${ }^{12}$. A placa foi incubada a $37^{\circ} \mathrm{C}$, por 72 horas. A cada 24 horas, o meio de cultura de cada poço foi coletado e substituído por meio BHI/glicose fresco.

Após 72 horas, os corpos de prova foram assepticamente removidos dos poços e transferidos para tubos contendo $\mathrm{NaCl}(0,9 \%)$ estéril. As amostras foram vortexadas e seriadamente diluídas. Alíquotas das diluições foram plaqueadas em AS e incubadas a $37^{\circ} \mathrm{C}$, por 24 horas. Após esse período, as unidades formadoras de colônia (UFC) foram contadas e a média para cada grupo, registrada como o número de bactérias viáveis, sendo os valores convertidos em uma escala logarítmica.

\section{Espectroscopia de infravermellho por transformada de Fourier}

A superfície externa dos tubos foi analisada por espectroscopia de infravermelho por transformada de Fourier (FTIR) para verificar alterações químicas 
após os diferentes reprocessamentos. A superfície externa de cada amostra foi posicionada em contato com o cristal de diamante de um dispositivo de refletância total atenuada (Platinum ATR-QL, Bruker Optics, Ettlingen, Alemanha), acoplado a um espectrofotômetro de infravermelho (Vertex 70, Bruker Optics, Ettlingen, Alemanha). As amostras foram irradiadas dezesseis vezes e um detector de infravermelho-médio (MIR ATR A225 Diamont, Bruker Optics, Ettlingen, Alemanha) capturou a radiação refletida. Espectros de absorbância foram obtidos com uma resolução de 4 $\mathrm{cm}^{-1}$ e comparados entre os grupos.

\section{Rugosidade}

Os mesmos corpos de prova utilizados para análise por FTIR tiveram a rugosidade da superfície externa aferida com rugosímetro de superfície portátil (SJ-201, Mitutoyo, Japão). Foi adotado o parâmetro de rugosidade $\mathrm{Ra}$, no qual a rugosidade é dada pela área dos picos e vales dividida pela distância percorrida $(0,25 \mu \mathrm{m})$ pelo sensor na superfície da amostra. A rugosidade Ra de cada amostra foi dada pela média aritmética de três leituras no sentido transversal e três leituras no sentido longitudinal do tubo.

\section{Recuperação após deformação}

Cinco cilindros com $10 \mathrm{~mm}$ de altura de cada grupo, obtidos pela secção transversal dos tubos, foram submetidos a uma carga compressiva de $150 \mathrm{~N}$, por 60 segundos, provocando o completo contato das paredes internas. $\mathrm{O}$ diâmetro interno dos tubos foi aferido antes da aplicação da carga e após 60 segundos da sua remoção. Para aferição do diâmetro, os tubos foram posicionados a uma distância de 100 $\mathrm{mm}$ de uma máquina fotográfica digital (DSC-W55, Sony, Brasil) e imagens com uma resolução de 72dpi foram adquiridas. As imagens foram transferidas para um software (Irfan Skiljan, Wiener Neustadt, Austria) e o diâmetro interno, medido no sentido da aplicação da carga, foi aferido em pixels. A medida do diâmetro final $\left(\mathrm{D}_{\mathrm{f}}\right)$ em relação ao diâmetro inicial $\left(D_{\mathrm{i}}\right)$ caracterizou a recuperação após a deformação (Rec) de cada amostra, em percentual, conforme a equação a seguir: $\operatorname{Rec}(\%)=\left(D_{\mathrm{f}} / \mathrm{D}_{\mathrm{i}}\right) \times 100$.

\section{Análise estatística}

Diferenças entre o número de bactérias viáveis, a rugosidade e a recuperação após a deformação entre os grupos foram analisadas utilizando-se ANOVA de uma via em um nível de significância de 5\%.

\section{Resultados}

A Tabela 1 apresenta a contagem de bactérias viáveis aderidas à superfície dos tubos, a rugosidade e a recuperação após a deformação obtida para os diferentes grupos. O número de bactérias viáveis $(p=0,235)$, a rugosidade $(p=0,621)$ e a recuperação após a deformação $(p=0,633)$ não foram influenciadas pelo número de imersões. A análise por FTIR (Figura 1) mostrou espectros característicos do PVC e revelou o desaparecimento do pico na região de $2.360 \mathrm{~cm}^{-1}$, referentes ao $\mathrm{CO}_{2}$ retido no polímero, não evidenciando alterações químicas significativas nos tubos. Os espectros obtidos para cada amostra de um mesmo grupo foram consistentes quanto aos picos presentes.

Tabela 1 - Contagem de bactérias viáveis, rugosidade e recuperação após deformação (\%) de acordo com o número de imersões em ácido peracético

\begin{tabular}{l|c|c|c}
\hline $\begin{array}{c}\text { Número de } \\
\text { imersões }\end{array}$ & $\begin{array}{c}\text { Bactérias viáveis } \\
(\log \cup F C / m l)\end{array}$ & $\begin{array}{c}\text { Rugosidade } \\
(\mu \mathrm{m})\end{array}$ & $\begin{array}{c}\text { Recuperação após } \\
\text { deformação }(\%)\end{array}$ \\
\hline Controle & $1,07 \pm 0,01$ & $0,14 \pm 0,04$ & $89,20 \pm 6,14$ \\
1 & $1,07 \pm 0,02$ & $0,17 \pm 0,07$ & $92,20 \pm 5,67$ \\
2 & $1,05 \pm 0,02$ & $0,20 \pm 0,11$ & $90,00 \pm 5,20$ \\
3 & $1,07 \pm 0,01$ & $0,13 \pm 0,04$ & $86,80 \pm 8,53$ \\
\hline
\end{tabular}

Fonte: Laboratório de Materiais Dentários; Laboratório de Bioquímica e Microbiologia Bucal.

Não houve diferença estatisticamente significativa para o número de bactérias viáveis $(\mathrm{p}=0,235)$, rugosidade $(\mathrm{p}=0,621)$ e recuperação após deformação $(p=0,633)$.

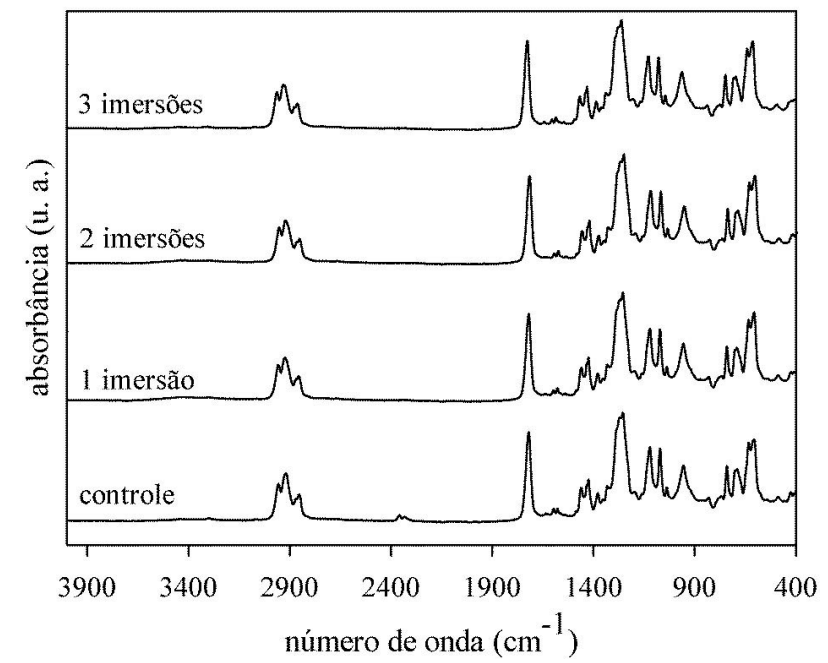

Figura 1 - Espectro representativo dos tubos endotraqueais após os diferentes processamentos dos tubos

Pode-se observar em todos os espectros os picos característicos do policloreto de vinila. Os picos nas bandas $2.950 \mathrm{~cm}^{-1} \mathrm{e} 2.930 \mathrm{~cm}^{-1}$ são referentes ao estiramento da ligação $-\mathrm{CH}_{-}$- e $-\mathrm{CH}$-, o pico em $1.725 \mathrm{~cm}^{-1}$ refere-se à ligação $\mathrm{C}=\mathrm{O}$, entre as bandas $1.100 \mathrm{~cm}^{-1}$ e $1.030 \mathrm{~cm}^{-1}$, notam-se os picos relativos às ligações $\mathrm{C}-\mathrm{Cl}$. Bandas relativas a vibrações angulares $-\mathrm{CH}_{2}-$ no plano podem ser observadas na região de $1.450 \mathrm{~cm}^{-1}$. O pico $2.360 \mathrm{~cm}^{-1}$, presente no espectro do grupo controle, refere-se a ligações do $\mathrm{CO}_{2}$ retido no polímero durante o processo de fabricação do tubo ${ }^{13,14}$

Fonte: Laboratório de Materiais Dentários. 


\section{Discussão}

Quando há necessidade de ventilação mecânica por intubação, seja para a realização de cirurgias com anestesia geral ou devido ao estado crítico do paciente com dificuldade de respiração, aumenta o risco de aspiração de patógenos até o trato respiratório inferior 4 . Os tubos endotraqueais representam a adição de uma ampla superfície passível de colonização bacteriana na cavidade bucal, podendo ser responsáveis por até $73 \%$ do total de bactérias na cavidade bucal ${ }^{15}$, o que leva a uma preocupação maior em casos de internação por longos períodos ${ }^{4}$. Portanto, faz-se necessária a desinfecção de tubos antes de sua reutilização, de maneira que suas propriedades sejam preservadas. No presente estudo, o processamento em ácido peracético por até três vezes não influenciou a capacidade de colonização da superfície dos tubos por Staphylococcus aureus, nem alterou a estrutura química, a rugosidade ou a capacidade de recuperar-se após receber uma carga que coloque em contato as paredes internas do tubo.

A contaminação por Staphylococcus aureus dos grupos experimentais não foi influenciada pelo número de imersões em ácido peracético. As análises por FTIR e de rugosidade mostraram que, mesmo após três imersões de 20 minutos, no desinfetante, a estrutura química do tubo e a sua topografia superficial não foram alteradas. Tal fato justifica 0 padrão de colonização bacteriana semelhante entre os grupos. Além disso, a avaliação da deformação do tubo pode indicar que também não ocorreu nenhum tipo de degradação interna no polímero. A manutenção das dimensões do tubo é importante para que, após a sua instalação, a passagem de ar não seja comprometida por eventuais compressões ao longo do tubo, afetando a ventilação do paciente.

Em relação à reutilização de dispositivos médicos, há três preocupações básicas de segurança: segurança da esterilização, integridade mecânica e de forma. A FDA decidiu no ano de 2000 que não proibiria a reutilização de aparatos inicialmente propostos para uso único, desde que o reprocessamento atendesse aos padrões originais do fabricante de garantia de qualidade e critérios de segurança ${ }^{9}$. Além disso, em uma época em que há grande preocupação com o desenvolvimento sustentável, torna-se necessário reduzir a produção de resíduos sólidos ${ }^{9}$.

Glutaraldeído, peróxido de hidrogênio, óxido de etileno e ácido peracético têm sido utilizados para desinfecção de alto nível de tubos endotraqueais. Uma avaliação da aderência de biofilme e integridade física de tubos endotraqueais esterilizados com glutaraldeído e óxido de etileno sugere que ambos os desinfetantes previnem a infecção cruzada, porém podem comprometer a integridade física dos tubos. Alterações na integridade física dos tubos endotraqueais foram constatadas após cinco reprocessamentos com glutaraldeído e três reprocessamentos com óxido de etileno ${ }^{16}$.
De acordo com os resultados do presente estudo, os tubos podem ser processados em ácido peracético por até três vezes, com segurança no que se refere aos ensaios executados neste trabalho. Ainda, o ácido peracético apresenta-se como uma alternativa de menor custo em relação aos demais desinfetantes químicos e é seguro para o operador e para o meio ambiente, não apresentando problemas de descarte, uma vez que o ácido peracético decompõe-se em água, peróxido de hidrogênio, oxigênio e ácido acético ${ }^{10}$.

Embora não tenham sido verificadas alterações nas propriedades químicas e mecânicas dos tubos endotraqueais e nem aumento na colonização bacteriana em decorrência das sucessivas imersões em ácido peracético, é importante ressaltar que os tubos foram avaliados após um máximo de três imersões, podendo um número maior de imersões comprometer a integridade dos tubos. Cabe ressaltar que os tubos utilizados no presente estudo não foram previamente utilizados em pacientes e, dessa forma, não é possível verificar se as sucessivas imersões em ácido peracético apresentam eficácia para esterilização da microbiota remanescente nos tubos após o primeiro uso. A avaliação da eficácia do reprocessamento nessas condições não é objetivo do presente trabalho e deve ser considerada previamente à reutilização de tubos.

\section{Conclusão}

A repetição de imersões em ácido peracético por até três vezes não influenciou a colonização da superfície por Staphylococcus aureus, composição química, rugosidade e capacidade de recuperar-se após deformação de tubos endotraqueais de PVC.

\section{Abstract}

Objective: This study aimed to assess the influence of repeated immersions in peracetic acid on bacterial colonization, chemical composition, roughness, and recovery ability after endotracheal tubes deformation. Materials and method: Four tubes were subjected to successive immersions in peracetic acid, forming four groups: a control group (sterilized by the manufacturer) and others subjected to one, two, or three immersions, in order to simulate reprocessing of tubes. Infrared spectroscopy, surface roughness, tube light deformation after compression, and Staphylococcus aureus colonization were assessed. Results: The number of immersions (reprocessing) had no influence on Staphylococcus aureus colonization of tubes $(p=0.235)$, neither on chemical composition nor on roughness $(p=0.621)$. Additionally, there was no difference in recovery ability after deformation ( $p=0.633)$. Conclusion: Reprocessing up to three times does not impair material properties and does not increase bacterial colonization of tube surfaces.

Keywords: Peracetic acid. Disinfection. Ventilator-associated Pneumonia. Artificial respiration. 


\section{Referências}

1. Fonseca L, Vieira FN, Azzolin KO. Fatores associados ao tempo de ventilação mecânica no pós-operatório de cirurgia cardíaca. Rev Gaúcha Enferm 2014; 35(2):67-72.

2. Raghavendran K, Millote JM, Scannapieccoet FA. Nursing home-associated pneumonia, hospital-acquired pneumonia and ventilator-associated pneumonia: the contribution of dental biofilms and periodontal inflammation. Periodontol 2000 2007; 44:164-77.

3. Cavalcanti M, Valencia M, Torres A. Respiratory nosocomial infections in the medical intensive care unit. Microbes Infect 2005; 7(2):292-301.

4. Garcia R. A review of the possible role of oral and dental colonization on the occurrence of health care-associated pneumonia: underappreciated risk and a call for interventions. Am J Infect Control 2005; 33:527-41.

5. Pace MA, Watanabe E, Facetto MP, Andrade D. Staphylococcus spp. na saliva de pacientes com intubação orotraqueal. Rev Panam Infectol 2008; 10(2):8-12.

6. Rutala WA, Weber DJ. Guideline for disinfection and sterilization in healthcare facilities: recommendations of the CDC. Healthcare Infection Control Practices Advisory Committee. MMWR Morb Mortal Wkly Rep, Chapel Hill: University of North Carolina School of Medicine; 2008.

7. Stoermer, WB Jr. Reprocessing 'single use' devices--why is there so much debate? Todays Surg Nurse 1999; 21(2):27-33.

8. Qian Z, Castaneda WR. Can labeled single-use devices be reused? An old question in the new era. J Vasc Interv Radiol 2002; 13(12):1183-6.

9. Food and Drug Administration - FDA issues final guidance on requirements governing single-use medical devices. Rep Med Guidel Outcomes Res 2000; 11:5-6.

10. Gehr R, Cochrane D, French M. Peracetic acid as a disinfectant for municipal wastewaters: encouraging performance results from physicochemical as well as biological effluents. Protocol of the US water environment federation disinfection conference; 2002.

11. Wessels S, Hanne I. Modes of action of three disinfectant active substances: a review. Regul Toxicol Pharmacol 2013; 33:456-67.

12. Waeiss RA, Negrini TC, Arthur RA, Bottino MC. Antimicrobial effects of drug-containing electrospun mats on osteomyelitis associated biofilms. Biofouling 2014; 72(7):1310-9.

13. Petránek V, Kosíková J. Infrared spectroscopy for determination degradation of polymers. Publishing House Education and Science. [periódico on-line] [citado 2016 jul. 26]. Disponível em URL: http:/www.rusnauka.com/31_PRNT_2008/ Stroitelstvo/36388.doc.htm.

14. Souza ML, Corio P, Temperini MLA, Temperini JA. Aplicação de espectroscopias raman e infravermelho na identificação e quantificação de plastificantes em filmes comerciais de PVC esticável. Quim Nova 2009; 32(6):1452-6.

15. Oliveira LC, Carneiro PP, Fischer RG, Tinoco EM. A presença de patógenos respiratórios no biofilme bucal de pacientes com pneumonia nosocomial. Rev Bras Ter Int 2007; 19(4):428-33.

16. Yoon SZ, Jeon YS, Kim YC, Lim YJ, Bahk JH, Do SH, et al. The safety of reused endotracheal tubes sterilized according to Centers for Disease Control and Prevention guidelines. J Clin Anesth 2007; 19(5):360-4

\section{Endereço para correspondência:}

Fernando Freitas Portella

Rua Sarmento Leite, 245 - Sala 722/Anexo II

Universidade Federal de Ciências da Saúde de Porto Alegre 90050-170 Porto Alegre, RS, Brasil

Telefone: (51) 3303-8859

E-mail: portellaff@yahoo.com.br

Recebido: 16/05/2016. Aceito: 26/09/2016. 